\title{
THE CHANGE OF COORDINATE SYSTEM VERSUS THE AREA OF PARCELS
}

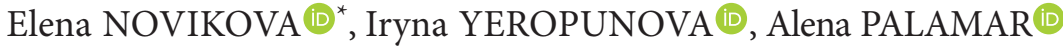 \\ Department of Geodesy, State Higher Educational Institution, Kryvyi Rih National University, \\ Kryvyi Rih, Ukraine
}

Received 07 December 2018; accepted 27 February 2020

\begin{abstract}
The transition from one coordinate system to another creates many problems, one of which is the change in the area of land parcels. There are at least three reasons causing a change in the area of the parcels after transition from one coordinate system to another. 1 . The change in area associated with the transition from one reference ellipsoid to another; 2. The change in area due to deformations caused by random and systematic errors of one of the coordinate systems; 3 . The change in the area of the parcel associated with the properties of the projection of Gauss-Krüger. It is shown that the greatest change in the area of the parcel during the transition from CS-63 to UCS-2000 (the coordinate systems of Ukraine) is associated with the properties of the Gauss-Krüger projection. For the parcel of 1 hectare, extreme changes in the area at the borders between the zones of the coordinate systems, can reach the size of $1.95 \mathrm{sq}$. $\mathrm{m}$. When using local coordinate systems based on UCS-2000, extreme area changes can reach 7.02 sq. m per 1 hectare. It is concluded that the difference in the areas of parcels caused by the properties of the Gauss-Krüger projection could have been avoided if the prime meridians of the zones in the UCS-2000 and CS-63 systems coincided.
\end{abstract}

Keywords: CS-63, UCS-2000, the area of land parcels, the Gauss-Krüger projection.

\section{Introduction}

At the heart of each national cadastral database is a coordinate system. The Baltic countries: Lithuania, Latvia, Estonia, since the beginning of the creation of the national land management system have successfully established high-precision coordinate systems that are rigidly and uniquely associated with the European coordinate system. This allowed geodesists of these countries to create competently and professionally the national Cadastre information systems (Petrulyte, 1998; Aleknavicius \& Sinkeviciute, 2008; Parsova et al., 2012), and to avoid a large number of problems associated with the transition from one coordinate system to another.

In Ukraine, the Cadastre information system began to be created in 1997 (Urozhay, 1998) on the basis of the CS-63 coordinate system. As a result, by the beginning of 2018, all land parcels (not less than 25 million) have coordinates in the old coordinate system CS-63. Public cadastral map of Ukraine (http://map.land.gov.ua/kadastrova-karta) built and functioning in CS-63. The transition to the new coordinate system, UCS-2000, has created a number of problems, one of which is the problem connected with the change of the area of the parcel during the transition from CS-63 to UCS-2000.

The paper considers the causes of the inequality the areas of the parcels calculated in different coordinate systems.

There are at least three reasons due to which the area of the parcel in one coordinate system is not equal to the area of the same parcel in another. The reasons are as following:

1. The difference between the centers and orientations of the axes of the spatial rectangular coordinates, and the difference between the parameters of the reference ellipsoids associated with these coordinates;

2. The deformations caused by random and systematic errors of one of the coordinate systems;

3 . The inequality of areas associated with the property of the Gauss-Krüger projection to distort the area.

\section{The area inequality caused by the transition from one reference ellipsoid to another}

During the transition from one reference ellipsoid to another, the geodetic coordinates of the point are change. Changes can be calculated using the equations (Rapp,

*Corresponding author. E-mail: elenanovikova131254@gmail.com 
1993; Molnár \& Timár, 2005; Standartinform, 2017):

$$
\begin{aligned}
\delta_{\varphi}= & \varphi_{C S 2}-\varphi_{C S 1}=\frac{1}{M}(-(\Delta X \cos \lambda+\Delta Y \sin \lambda) \sin \varphi+ \\
& \Delta Z \cos \varphi)+\left(R_{X} \sin \lambda-R_{Y} \cos \varphi\right)\left(1+e^{2} \cos 2 \varphi\right)- \\
& \frac{1}{2} \mu \cdot e^{2} \sin 2 \varphi+\frac{\sin 2 \varphi \cdot N}{2 M}\left(\frac{\Delta a}{a} e^{2}+\left(\frac{N^{2}}{a^{2}}+1\right) \frac{\Delta e^{2}}{2}\right) ;(1) \\
\delta_{\lambda}= & \left(\lambda_{C S 2}-\lambda_{C S 1}\right)=\frac{1}{r}(-\Delta X \sin \lambda+\Delta Y \cos \lambda)- \\
& \tan \varphi\left(1-e^{2}\right)\left(R_{X} \cos \lambda+R_{Y} \sin \lambda\right)+R_{Z},
\end{aligned}
$$

where $\varphi_{C S 1}, \lambda_{C S 1}, \varphi_{C S 2}, \lambda_{C S 2}$ are geodetic latitude, longitude of a point in the first (the coordinate system CS1) and in the second reference ellipsoids (the coordinate system CS2); $\Delta X, \Delta Y, \Delta Z$ are the Helmert's linear transformation parameters during the transition from CS1 to CS2; $R_{X}, R_{Y}, R_{Z}$ are the Helmert's angular transformation parameters, called "position vector rotation", according to (Timár \& Molnár, 2013); $\mu$ is the scale factor; $\varphi, \lambda$ are the geodetic latitude, longitude of a point on the ellipsoid of one the coordinate system, for example CS1; $M$ is the radius of curvature in the meridian; $r$ is the radius of parallel; $a$ is the semi-major axis; $e^{2}$ is the square of the first eccentricity of one of the ellipsoid, for example, the ellipsoid of the coordinate system CS1; $\Delta a, \Delta e^{2}$ are the difference between the semi-major axes and the difference between the squares of the eccentricities the second and the first coordinate systems, namely:

$$
\Delta a=a_{C S 2}-a_{C S 1}, \Delta e^{2}=e_{C S 2}^{2}-e_{C S 1}^{2} .
$$

Since there is one ellipsoid (the Krassovsky 1940 ellipsoid), with geometrical parameters: $a=6378245$ (m), $e^{2}=0.006693421623$ (Zakatov, 1962), used in CS-63 and UCS-2000, then:

$\Delta a=a_{U C S 2000}-a_{C S 63}=0, \Delta e^{2}=e_{U C S 2000}^{2}-e_{C S 63}^{2}=0$.

In this case, equation (1) is written as:

$$
\begin{aligned}
& \delta_{\varphi}=\varphi_{C S 2}-\varphi_{C S 1}= \\
& \frac{1}{M}(-(\Delta X \cos \lambda+\Delta Y \sin \lambda) \sin \varphi+\Delta Z \cos \varphi)+ \\
& \left(R_{X} \sin \lambda-R_{Y} \cos \varphi\right)\left(1+e^{2} \cos 2 \varphi\right)-\frac{1}{2} \mu \cdot e^{2} \sin 2 \varphi .
\end{aligned}
$$

The parameters of the Helmert's transformation from CS-63 to UCS-2000, used in equations (1-5), can be obtained by the transformation parameters of these systems with the WGS-84 system. Since the CS-63 and CS-42 systems are tied to one spatial rectangular coordinate system, Pulkovo 1942, the transformation parameters from CS-63 to WGS-84 completely coincide with the transformation parameters from CS-42 to WGS-84. The transformation parameters for Ukraine from CS-42 to WGS-84 are presented on the website epsg.io (https:// epsg.io/15865) (Table 1). The transformation parameters between WGS-84 and UCS-2000 are taken from (Novikova et al., 2018).
Table 1. Helmert parameters for the transformation of coordinates between the CS-63 (CS-42), WGS-84, UCS-2000

\begin{tabular}{|l|c|c|c|}
\hline \multicolumn{1}{|c|}{ Parameter } & $\begin{array}{c}\text { from CS-63 } \\
\text { (CS-42) to } \\
\text { WGS-84 }\end{array}$ & $\begin{array}{c}\text { from WGS- } \\
2000\end{array}$ & $\begin{array}{c}\text { from CS-63 } \\
\text { (CS-42) to } \\
\text { UCS-2000 }\end{array}$ \\
\hline Epoch & - & 2005 & - \\
\hline$\Delta X(\mathrm{~m})$ & 25.0 & -24.3234 & 0.7 \\
\hline$\Delta Y(\mathrm{~m})$ & -141.0 & 121.3708 & -19.6 \\
\hline$\Delta Z(\mathrm{~m})$ & -78.5 & 75.8275 & -2.7 \\
\hline$R_{X}(\operatorname{arc~sec})$ & 0.000 & 0.00000 & 0.000 \\
\hline$R_{Y}(\operatorname{arc~sec})$ & 0.350 & 0.00000 & 0.350 \\
\hline$R_{Z}(\mathrm{arc} \mathrm{sec})$ & 0.736 & 0.00000 & 0.736 \\
\hline$\mu(\mathrm{ppb})$ & 0.0 & 1.74 & 1.7 \\
\hline
\end{tabular}

The transformation parameters from CS-63 to UCS2000 (Table 1) are obtained by means of the rule formulated in (Novikova et. al., 2018) according to which, if all the angular parameters and the scale factor are the firstorder quantities of the smallness, then the parameters of the Helmert transformation for the transition from the first to the $\mathrm{n}$-th coordinate system are equal to the sum of the corresponding parameters between all the previous coordinate systems obtained for one epoch.

The area element of the ellipsoid surface of revolution obtained by next formula (Rapp, 1991):

$$
d P=M d \varphi \cdot r d \lambda,
$$

where $M d \varphi$ is the differencial of metidain length, $r d \lambda$ is the differencial of parallel length.

There are several closed and approximate formulae (Zakatov, 1962; Rapp,1991) for calculating the area of the spheroidal trapezium between two meridians with longitudes $\lambda_{1}, \lambda_{2}$ and parallels with latitudes $\varphi_{1}, \varphi_{2}$, obtained by integrating the equality (6). However, to calculate the small areas, several hectares in size, it is possible to replace the differentials by finite differences in the equality (6) and using Cauchy's Mean Value Theorem and the formulae for the connection of $M, r$ to the geodetic latitude $\varphi$ (Rapp, 1991), to write down:

$$
P \cong \frac{a^{2}\left(1-e^{2}\right)}{\left(1-e^{2} \sin ^{2} \varphi_{m}\right)^{2}} \cos \varphi_{m} \Delta \varphi \Delta \lambda,
$$

where:

$$
\Delta \varphi=\varphi_{2}-\varphi_{1}, \varphi_{m}=\frac{1}{2}\left(\varphi_{2}+\varphi_{1}\right), \Delta \lambda=\lambda_{2}-\lambda_{1} .
$$

For the parcel in CS-63, equality (7) is written as:

$$
P_{C S 63} \cong \frac{a^{2}\left(1-e^{2}\right)}{\left(1-e^{2} \sin ^{2} \varphi_{m}\right)^{2}} \cos \varphi_{m} \Delta \varphi_{C S 63} \Delta \lambda_{C S 63},
$$

where:

$$
\Delta \varphi_{C S 63}=\varphi_{2}-\varphi_{1}, \Delta \lambda_{C S 63}=\lambda_{2}-\lambda_{1} .
$$


Similarly, for the parcel in UCS-2000:

$$
\begin{aligned}
& P_{U C S 2000}=\frac{a^{2}\left(1-e^{2}\right)}{\left(1-e^{2} \sin ^{2}\left(\varphi_{m}+\delta_{\varphi}\right)\right)^{2}} \times \\
& \cos \left(\varphi_{m}+\delta_{\varphi}\right) \Delta \varphi_{U C S 2000} \Delta \lambda_{U C S 2000},
\end{aligned}
$$

where:

$$
\begin{aligned}
& \Delta \varphi_{U C S 2000}=\left(\varphi_{2}+\delta_{\varphi 2}\right)-\left(\varphi_{1}+\delta_{\varphi 1}\right), \\
& \Delta \lambda_{U C S 2000}=\left(\lambda_{2}+\delta_{\lambda 2}\right)-\left(\lambda_{1}+\delta_{\lambda 1}\right) .
\end{aligned}
$$

As the coordinates change from $\varphi_{1}, \lambda_{1}$ to $\varphi_{2}, \lambda_{2}$, the values $\delta_{\varphi}, \delta_{\lambda}$, calculated by equations $(2,5)$, change slowly enough and affect the coordinates of small parcel in the same direction and in the same way, the same changes of coordinates $\varphi, \lambda$ take place for all points of the parcel. This means that for small areas:

$$
\begin{aligned}
& \delta_{\varphi 1} \cong \delta_{\varphi 2}, \delta_{\lambda 1} \cong \delta_{\lambda 2} ; \\
& \Delta \varphi_{U C S 2000} \cong \Delta \varphi_{C S 63}=\Delta \varphi ; \\
& \Delta \lambda_{U C S 2000} \cong \Delta \lambda_{C S 63}=\Delta \lambda .
\end{aligned}
$$

The difference of areas between the parcel on the ellipsoid in UCS-2000 and the same parcel on the ellipsoid in CS-63, according to the formulae $(11,12,14)$, is equal to:

$\delta P^{(1)} \cong \frac{a^{2}\left(1-e^{2}\right)}{\left(1-e^{2} \sin ^{2} \varphi_{m}\right)^{2}} 2 \sin \left(\frac{2 \varphi_{m}+\delta_{\varphi}}{2}\right) \sin \left(\frac{-\delta_{\varphi}}{2}\right) \Delta \varphi \Delta \lambda$.

Assuming that $\delta_{\varphi}$ is the value of the first order of smallness, ignoring the values of the second order of smallness, equality (15) gives:

$$
\delta P^{(1)} \cong-\delta_{\varphi} \frac{a^{2}\left(1-e^{2}\right)}{\left(1-e^{2} \sin ^{2} \varphi_{m}\right)^{2}} \sin \varphi_{m} \Delta \varphi \Delta \lambda .
$$

Using equality (9), the following formula can be derived:

$$
\delta P^{(1)} \cong-\delta_{\varphi} \tan \varphi_{m} P_{C S 63} .
$$

In formula (17), $\delta_{\varphi}$ is determined using equality (5) with the transformation parameters from CS-63 to UCS2000, presented in Table 1.

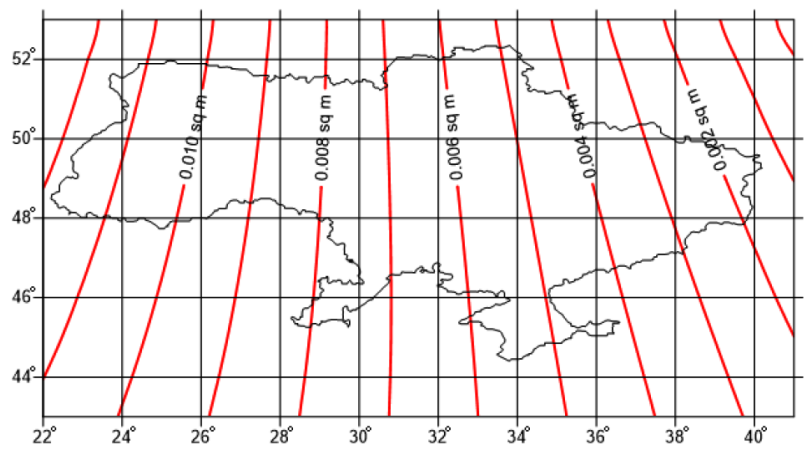

Figure 1. Isolines of $d P^{(1)}$, calculated for the parcels of 1 hectare for the territory of Ukraine
In Figure 1 there is the isolinear graph of $\delta P^{(1)}$, calculated for the parcels of area, equal 1 hectare. The isolines are drawn through 0.001 sq. $m$. According to this graph, the largest value of $\delta P^{(1)}$, equal to 0.012 sq. $\mathrm{m}$, takes place in the west of Ukraine, the smallest -0.001 sq. $\mathrm{m}$ - in the east.

\section{The change in the area of the parcels associated with the deformations between CS-63 and UCS-2000}

Deformations, caused by systematic and random errors of CS-63 (CS-42) and detected when the UCS-2000 system is used, are investigated in detail by (Kucher, 2012). The largest difference between the spatial rectangular coordinates of points in both systems, according to (Kucher, 2012 ) is $3.5 \mathrm{~m}$. This value holds for points on the border of Ukraine. In the center of the country, the deformations are equal to zero. They vary smoothly, without jumps and gaps, from 0 to $3.5 \mathrm{~m}$ when moving from the central points of the country to the periphery.

The maximum area changes caused by deformations occur in those points in the country where the slope of the deformation surface is maximum, that is, in the parcels where the distance between the isolines of equal deformations is minimal.

According to the scheme of deformations, presented in (Kucher, 2012), the maximal slope of the deformation surface is in the center of the country in the region with geodetic coordinates:

$$
30^{\circ} 30.3^{\prime} \leq \lambda \leq 30^{\circ} 43.5^{\prime}, 49^{\circ} 47.8^{\prime} \leq \varphi \leq 49^{\circ} 52.5^{\prime} .
$$

The distance between the isolines of deformation in these areas is the minimum; defined by the scheme (Kucher, 2012), it turned out to be $18000 \mathrm{~m}$. Since the isolines are drawn through $0.5 \mathrm{~m}$, the slope corresponding to this distance is:

$$
i_{\max }=\frac{0.5}{18000}=2.77 \cdot 10^{-5}
$$

The area of the parcel according to the coordinates of the boundary points is calculated by means of the wellknown Gauss formula (Torge, 2001):

$$
P=\frac{1}{2} \sum_{j=1}^{N} X_{j}\left(Y_{j+1}-Y_{j-1}\right),
$$

where $N$ is the number of boundary points of the parcel, $X_{j}, Y_{j}$ are the coordinates of the $\mathrm{j}$-th boundary point.

Since the area is invariant with respect to the rectangular coordinate system on the plane, the system can be chosen so that the $\mathrm{X}$ axis should coincide with the direction of the maximum slope of the deformation surface; the $\mathrm{Y}$ axis is perpendicular to this direction. In this case, the deformation affect only on the coordinates $X$ of the parcel. $Y$ coordinates will remain unchanged.

The coordinates $X_{j}^{D}$ of the deformed parcel can be calculated by the formula:

$$
X_{j}^{D}=X_{j}+d_{j}
$$


where $X_{j}$ is the coordinate of the undeformed parcel, $d_{j}$ is the value of deformation at the $j$-th point.

The area of the deformed parcel is determined from the equation:

$$
P^{D}=\frac{1}{2} \sum_{j=1}^{N} X_{j}^{D}\left(Y_{j+1}-Y_{j-1}\right)=P+\frac{1}{2} \sum_{j=1}^{N} d_{j}\left(Y_{j+1}-Y_{j-1}\right),
$$

where $P$ is the area of the undeformed parcel.

Thus, the area distortion caused by deformations between coordinate systems can be determined from the equality:

$$
\delta P^{(2)}=P^{D}-P=\frac{1}{2} \sum_{j=1}^{N} d_{j}\left(Y_{j+1}-Y_{j-1}\right) .
$$

If it is assumed that the deformations inside the parcel act linearly, the slope, $i$, is a constant value, then:

$$
d_{j}=i \cdot X_{j}+D,
$$

where $D$ is the deformation value at the origin, at $X=0$.

Substitution (23) into (22) yields:

$$
\delta P^{(2)}=\frac{1}{2} \sum_{j=1}^{N}\left(i \cdot X_{j}+D\right)\left(Y_{j+1}-Y_{j-1}\right)=i \cdot P .
$$

For a parcel with area of 1 hectare, located along the line of maximum slope of the deformation surface, given (18), the change in area is equal to:

$$
\delta P^{(2)}=0.277 \text { (sq. m). }
$$

The value of 0.277 sq. $m$ is the maximum value of the change in the area of the parcel of 1 hectare, caused by deformations between the UCS-2000 and CS-63 (CS-42) coordinate systems. Unfortunately, the sign of the deformation is not indicated in (Kucher, 2012), therefore it is impossible to determine the area increases or decreases as a result of the deformation. In order to account accurately changes in the area caused by deformations between coordinate systems, it is necessary to determine the slope of the deformation surface in each region of the country.

\section{The change in the area of the parcels associated with the properties of the Gauss-Krüger projection}

The scale of lengths in the Gauss-Krüger projection for a zone with a width not exceeding 6 degrees in longitude, according to (Bugaevskij \& Snyder, 1995; Stuifbergen, 2009), is equal to:

$$
m \cong 1+\frac{1}{2}\left(\lambda-\lambda_{0}\right)^{2} \cos ^{2} \varphi\left(1+e^{\prime 2} \cos ^{2} \varphi\right),
$$

where $\lambda_{0}$ is the longitude of prime meridian (the longitude of origin), along which the length scale is equal to 1 ; $e^{\prime 2}$ is the square of the second eccentricity of the ellipsoid, equal to Krasovsky's ellipsoid (Zakatov, 1962):

$$
e^{\prime 2}=0.006738525415 \text {. }
$$

The scale of the area in the Gauss-Krüger projection, as in any other conformal projection (Bugaevskij \& Snyder, 1995), is:

$$
p=m^{2} \cong 1+\left(\lambda-\lambda_{0}\right)^{2} \cos ^{2} \varphi\left(1+e^{\prime 2} \cos ^{2} \varphi\right),
$$

As it is known (Bugaevskij \& Snyder, 1995), the scale of the area is the ratio of the area of an elementary figure in a projection in a certain coordinate system to the area of an elementary figure on an ellipsoid in the same system. For an ellipsoid in UCS-2000 the scale of the area is equal to:

$$
\begin{aligned}
P_{U C S 2000}= & \frac{d P_{p l, U C S 2000}}{d P_{\text {ell,UCS2000 }}} \cong 1+\left(\lambda_{U C S 2000}-\lambda_{0, U C S 2000}\right)^{2} \times \\
& \cos ^{2} \varphi_{U C S 2000}\left(1+e^{\prime 2} \cos ^{2} \varphi_{U C S 2000}\right) .
\end{aligned}
$$

In equality (27) $d P_{p l, U C S 2000}, d P_{\text {ell,UCS2000 }}$ are the area of the elementary figure on the plane and on the ellipsoid in the UCS-2000 system, respectively, $\varphi_{U C S 2000}, \lambda_{U C S 2000}$ are the coordinates of the point on the ellipsoid, latitude and longitude, in UCS-2000, $\lambda_{0, U C S 2000}$ is the longitude of the prime meridian of the zone in the Gauss-Krüger projection in UCS-2000.

Similarly, for the scale of the area in CS-63:

$$
\begin{aligned}
p_{C S 63}= & \frac{d P_{p l, C S 63}}{d P_{e l l, C S 63}} \cong 1+\left(\lambda_{C S 63}-\lambda_{0, C S 63}\right)^{2} \times \\
& \cos ^{2} \varphi_{C S 63}\left(1+e^{\prime 2} \cos ^{2} \varphi_{C S 63}\right) .
\end{aligned}
$$

Using the properties of trigonometric and inverse functions, based on the formulae $(2,5)$, the following inequalities can be derived for UCS-2000 and CS-63:

$$
\begin{gathered}
\left|\varphi_{U C S 2000}-\varphi_{C S 63}\right|<\frac{1}{a\left(1-e^{2}\right)}(|\Delta X|+|\Delta Y|+|\Delta Z|)+ \\
\left(\left|R_{X}\right|+\left|R_{Y}\right|\right)\left(1+e^{2}\right)+\frac{1}{2}|\mu| e^{2} ; \\
\left|\lambda_{U C S 2000}-\lambda_{C S 63}\right|<\frac{1}{\cos \varphi_{\max }}\left(\frac{1}{a}(|\Delta X|+|\Delta Y|)+\right. \\
\left.\left(\left|R_{X}\right|+\left|R_{Y}\right|+\left|R_{Z}\right|\right)\right),
\end{gathered}
$$

where $\varphi_{\max }$ is the maximum value of latitude for the territory in question. In particular, for Ukraine, the maximum value of latitude is:

$$
\varphi_{\max } \approx 52.4^{\circ} \text {. }
$$

Substitution of the data presented in Table 1 gives the following estimates:

$$
\begin{aligned}
& \left|\varphi_{U C S 2000}-\varphi_{C S 63}\right|<5.3351 \mathrm{E}-06=1.1 \mathrm{arc} \mathrm{sec}, \\
& \left|\lambda_{U C S 2000}-\lambda_{C S 63}\right|<1.3828 \mathrm{E}-05=2.9 \text { arc sec. }
\end{aligned}
$$

Neglecting these values, can be written:

$$
\varphi_{U C S 2000}=\varphi_{C S 63}=\varphi, \quad \lambda_{U C S 2000}=\lambda_{C S 63}=\lambda \text {. }
$$

As shown in Section 1, the difference between the area of a parcel of 1 hectare in size on the ellipsoid in the 
UCS-2000 and CS-63 systems is not more than 0.012 sq. $\mathrm{m}$. As will be shown below, the difference between the area of a parcel in the Gauss-Krüger projection in the UCS-2000 and CS-63 systems is an order of magnitude larger than this value, therefore, the following equation can be written:

$$
d P_{\text {ell }, \text { UCS2000 }} \cong d P_{\text {ell, CS63 }} .
$$

The equality (27) being divided by (28) with (31-32) becomes:

$$
\frac{d P_{p l, U C S 2000}}{d P_{p l, C S 63}} \cong \frac{1+\left(\lambda-\lambda_{0, U C S 2000}\right)^{2} \cdot \Phi}{1+\left(\lambda-\lambda_{0, C S 63}\right)^{2} \cdot \Phi},
$$

where:

$$
\Phi=\cos ^{2} \varphi\left(1+e^{\prime 2} \cos ^{2} \varphi\right) .
$$

For small land parcels, area elements can be replaced by the areas themselves, i.e.

$$
\frac{P_{p l, U C S 2000}}{P_{p l, C S 63}} \cong \frac{1+\left(\lambda-\lambda_{0, U C S 2000}\right)^{2} \cdot \Phi}{1+\left(\lambda-\lambda_{0, C S 63}\right)^{2} \cdot \Phi} .
$$

In this case, the values $\varphi, \lambda$ are the average geodetic coordinates of the land boundary points.

Since $\left(\lambda-\lambda_{0, \text { CS63 }}\right)^{2} \cdot \Phi$ is the value of the first order of smallness that is much smaller than 1 , the discarding of the values of the second order of smallness yields:

$$
\frac{P_{p l, U C S 2000}}{P_{p l, C S 63}} \cong\left(1+\left(\lambda-\lambda_{0, U C S 2000}\right)^{2} \Phi\right) \cdot\left(1-\left(\lambda-\lambda_{0, C S 63}\right)^{2} \Phi\right) \text {. }
$$

By opening the parentheses and leaving only the values of the first order of smallness, after identical transformations, the equality (36) is written as:

$$
P_{p l, U C S 2000} \cong\left(1+2\left(\lambda_{0, C S 63}-\lambda_{0, U C S 2000}\right)\left(\lambda-\lambda_{m}\right) \Phi\right) P_{p l, C S 63} \text {, }
$$

where:

$$
\lambda_{m}=\frac{\lambda_{0, \mathrm{UCS} 2000}+\lambda_{0, \mathrm{CS} 63}}{2} .
$$

Considering the equality (37), the difference between the area of a parcel in UCS-2000 and CS-63 systems in the Gauss-Krüger projection can be found by:

$$
\begin{gathered}
\delta P^{(3)}=P_{p l, U C S 2000}-P_{p l, C S 63} \cong \\
2\left(\lambda_{0, C S 63}-\lambda_{0, U C S 2000}\right) \cdot\left(\lambda-\lambda_{m}\right) \cdot \Phi \cdot P_{p l, C S 63 .}
\end{gathered}
$$

Longitudes in the equation (39) are used in radians.

Based on formula (39), it can be concluded that the difference in area caused by the properties of the Gauss- Krüger projection can be avoided if the prime meridians of the zones in the UCS-2000 and CS-63 systems will be coincide.

The prime meridians of the zones in the Gauss-Krüger projection for the above-mentioned systems are:

$$
\begin{aligned}
& \lambda_{0, C S 63}: 23.5^{\circ}, 26.5^{\circ}, 29.5^{\circ}, 32.5^{\circ}, 35.5^{\circ}, 38.5^{\circ} ; \\
& \lambda_{0, U C S 2000}: 21^{\circ}, 24^{\circ}, 27^{\circ}, 30^{\circ}, 33^{\circ}, 36^{\circ}, 39^{\circ} .
\end{aligned}
$$

Figure 2 presents a graph of changes $\delta P^{(3)}$ depending on longitude for a land parcel with an area of 1 hectare along the parallel with latitude $\varphi=49^{\circ}$ and for longitudes from $20^{\circ}$ to $41^{\circ}$.

In the lower part of the graph, zones and prime meridians (in red) of the CS-63 system are shown, similarly in the upper part zones and prime meridians of the UCS2000 are shown.

As can be seen from the graph, the extreme differences between the areas of parcel in the UCS-2000 and CS-63 coordinate systems occur at the boundaries of the zones. Moreover, on the borders of the zones of the UCS2000 system there is a maximum value of $\delta P^{(3)}$, equals 1.64 sq. $\mathrm{m}$, on the borders of the zones of the CS-63 system - the minimum value equals to -1.64 sq. $\mathrm{m}$. Extreme values $\delta P^{(3)}$ depend on latitude. According to (38), the

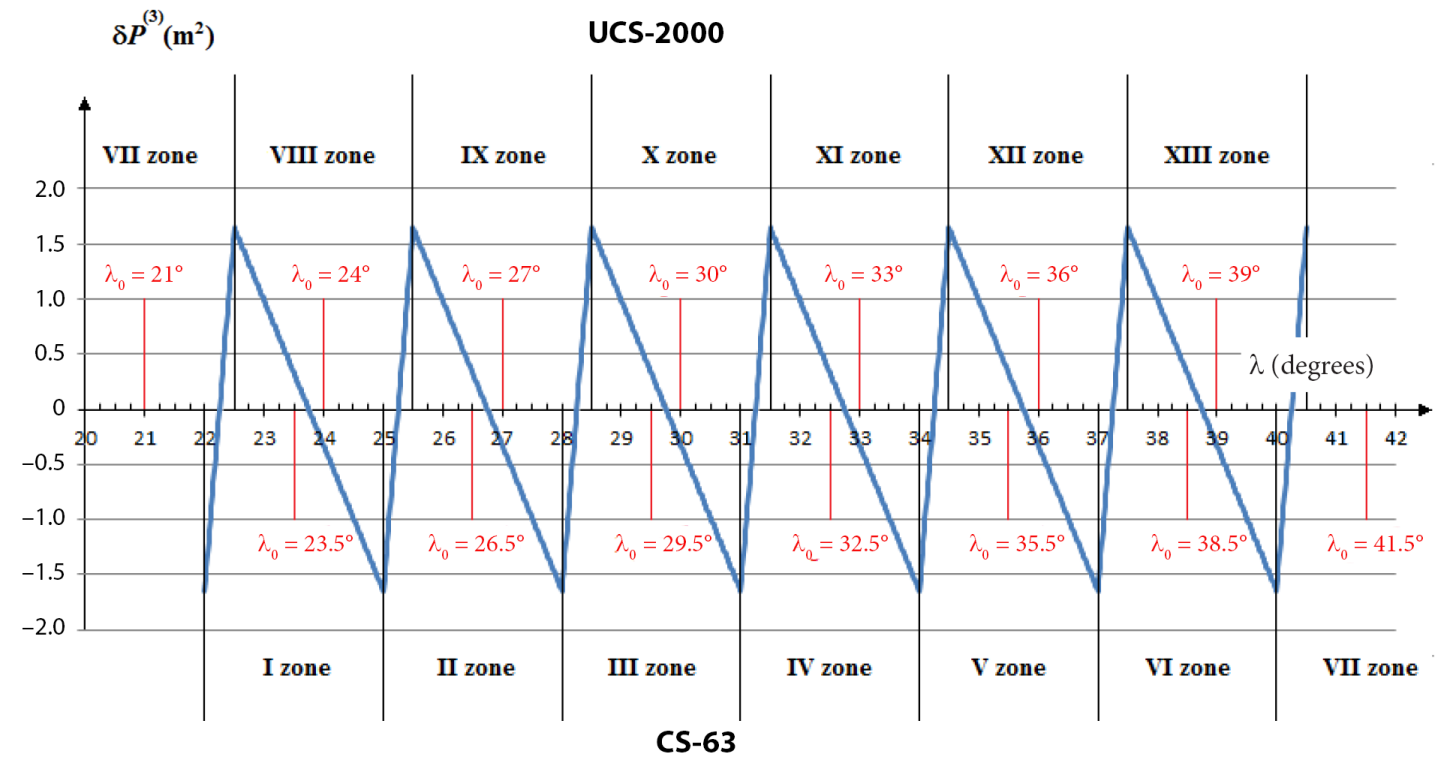

Figure 2. Graph of change $\delta P^{(3)}$ depending on longitude along the parallel with latitude $\varphi=49^{\circ}$ for a parcel of 1 hectare in the CS-63 system 
further south the parallel, the greater the extreme value $\delta P^{(3)}$.

The extreme value $\delta P^{(3)}$, depending on the latitude, can be obtained by substituting the product of values $2\left(\lambda_{0, C S 63}-\lambda_{0, \text { UCS2000 }}\right) \cdot\left(\lambda-\lambda_{m}\right)$ in the equation (38) in the case, when $\lambda$ is equal to any of the prime meridians.

Substituting specific values of $\lambda_{0, U C S 2000}, \lambda_{0, C S 63}, \lambda_{m}, \lambda$ into formula (39), it can be written as:

$$
\delta P_{\text {sup }}^{(3)}= \pm 3.807 \cdot 10^{-4} \cos ^{2} \varphi\left(1+e^{\prime 2} \cos ^{2} \varphi\right) P_{p l, C S 63}
$$

If the area of the parcel is 1 hectare, then for $\varphi=44^{\circ} 20^{\prime}$ (the southernmost latitude of Ukraine), $\delta P_{\text {sup }}^{(3)}= \pm 1.95$ sq. $\mathrm{m}$. Similarly, for $B=52^{\circ} 30^{\prime}$ (the northernmost latitude of Ukraine). $\delta P_{\text {sup }}^{(3)}= \pm 1.41$ sq. $\mathrm{m}$.

Thus, the greatest change in the area of the parcel is associated with the properties of the Gauss-Krüger projection. When using the UCS-2000 system, this value is within:

$\left|\begin{array}{l}\delta P^{(3)} \\ \text { tare. }\end{array}\right| \leq 1.95$ sq. $m$. for the parcel with area, equals 1 hec-

For cadastral surveys, according to (Minahropolityky, 2016), not only UCS-2000 can be used, but local coordinate systems associated with UCS-2000 as well. Each local system is designed so that only one zone is used within it. This allows geodesists to perform topographic surveys in only one zone without transitions from zone to zone. Each local zone has its own prime meridian. For instance, the local system LCS-35, developed for the Kirovograd region, has a prime meridian (see Figure 3 ) $\lambda_{0}=32^{\circ}$, and boundary meridians (Derzhheokadastr, n.d.):

$$
\lambda_{\text {East }}=33^{\circ} 55.5^{\prime}, \lambda_{\text {West }}=29^{\circ} 42.2^{\prime} .
$$

The difference in longitude of the boundary meridians LCS-35 is one of the largest in comparison with the differences in the longitude of other local systems and equal:

$$
\Delta \lambda_{W-E}=\lambda_{\text {East }}-\lambda_{\text {West }}=4^{\circ} 13.3^{\prime} .
$$

The use of local coordinate systems further increases the difference in the area of the parcel. The Figure 3 shows the graph of area change during the transition from

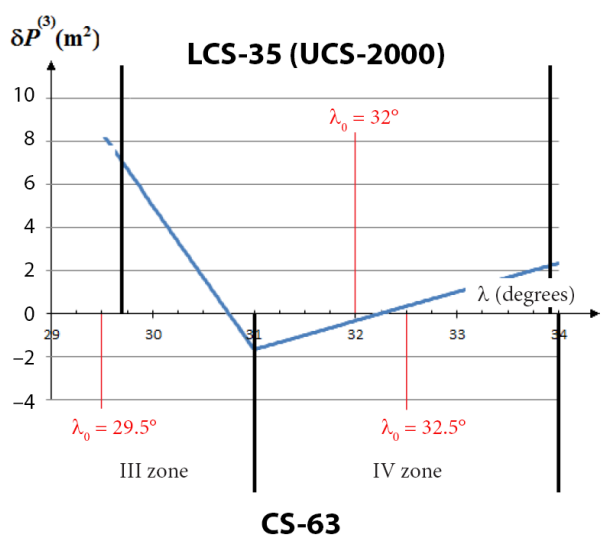

Figure 3. Graph of change $\delta P^{(3)}$ depending on longitude along the parallel with latitude $\varphi=48.5^{\circ}$ for a parcel of 1 hectare in the transition from CS-63 to LCS-35
CS-63 to LCS-35 along the parallel $\varphi=48.5^{\circ}$ for a parcel of 1 hectare. In the upper part of the graph, vertical black lines show the boundaries of the LCS-35, in the lower part - the boundaries of the CS-63 zones.

As can be seen from the graph in Figure 3, on the western border of the LCS-35, $\delta P^{(3)}$ reaches the maximum value of 7.020 sq. $m$, on the eastern border - the maximal value $2.247 \mathrm{sq}$. $\mathrm{m}$. On the border between zones III and IV, it reaches the minimum value of -1.677 sq. $\mathrm{m}$.

According to Figures $2-3$, the function $\delta P^{(3)}$ changes in a zigzag-like manner and between the zone boundaries is linear. At the zone boundaries, the derivative of the function $\delta P^{(3)}$ has a discontinuity of the first kind.

If for calculating $\delta P^{(3)}$ the average longitude of the points of the land parcel is not known with the required accuracy, it can be replaced by the average ordinate by means of the formula (Zakatov, 1962; Bugaevskij \& Snyder, 1995; Stuifbergen, 2009):

$$
\lambda-\lambda_{0} \approx \frac{y(\text { Easting })}{r},
$$

where $r$ is the radius of the parallel on the ellipsoid, which in the first approximation can be replaced by the radius of the parallel on the globe using (Zakatov, 1962; Bugaevskij \& Snyder, 1995):

$$
r=R \cos \varphi, R=6378000 \mathrm{~m} \text {. }
$$

Equality (41) for CS-63 and for any LCS looks as follows:

$$
\lambda-\lambda_{0, L C S} \approx \frac{y_{L C S}}{r}, \lambda-\lambda_{0, C S 63} \approx \frac{y_{C S 63}}{r},
$$

where $y_{C S 63}, y_{L C S}$ is the average ordinate of points of the land parcel boundary in the Gauss-Krüger projection in the CS-63 and any LCS systems, respectively.

By tradition, in the final form, the ordinates of points in the Gauss-Krüger projection change by a certain positive value. For the CS-63 and LCS systems, this value is equal to $300000 \mathrm{~m}$. Also in the CS-63 system, to the ordinate is added the value $n \cdot 1000000$ ( $n$ is the zone number in the CS-63 system). Therefore, the final ordinates in the systems CS-63 and LCS are determined from the ratios:

$$
Y_{C S 63}=y_{C S 63}+3 \cdot 10^{5}+n \cdot 10^{6}, Y_{L C S}=y_{L C S}+3 \cdot 10^{5} \text {. }
$$

Summation of formulae (43) and dividing the result by 2 taking into account (44) gives:

$$
\lambda-\lambda_{m} \approx \frac{Y_{C S 63}+Y_{L C S}-6 \cdot 10^{5}-n \cdot 10^{6}}{r} .
$$

Substitution (45) into (39) gives:

$\delta P^{(3)} \cong \frac{1}{R}\left(\lambda_{0, C S 63}-\lambda_{0, L C S}\right) \cdot\left(\bar{Y}-6 \cdot 10^{5}-n \cdot 10^{6}\right) \cdot \Phi \cdot P_{C S 63}$,

where:

$$
\bar{Y}=Y_{C S 63}+Y_{L C S} \text {. }
$$

In the Equations (46)-(47) $Y_{C S 63}, Y_{L C S}$ are the arithmetic average of the ordinates of the boundary points of 
the parcel. If the parcel is small, then it is possible to use in the formulae (46)-(47) the ordinates of one, arbitrarily chosen point of the parcel.

In the worst case, the total amount of change in the area of the parcel, caused by the transition from the coordinate system CS-63 to the coordinate system LCS-35 (UCS-2000) is

$$
\begin{aligned}
& \delta P_{\max }=\delta P_{\max }^{(1)}+\delta P_{\max }^{(2)}+\delta P_{\max }^{(3)}=7.020+0.277+ \\
& 0.012=7.309 \text { (sq. } \mathrm{m})=0.0007 \text { ha. }
\end{aligned}
$$

Since, the area of the parcel in the documentation is traditionally shown with an accuracy of 0.0001 hectare, the use of the coordinates of different systems, CS-63 and UCS-2000, leads to a difference in areas when the parcel has area more than 0.1 hectare and located near the border zone. To avoid this difference, state registrars require the documentation for parcels in which the area in the above mentioned systems are completely identical. In this case the area of the parcel in the system UCS-2000 is formally equals to the area of the parcel in the system CS-63. Thus, the CS-63 system, which was abolished de jure by a (Minahropolityk, 2016), continues to exist de facto in the areas of the parcels.

Having made sure of the unsuitability of the non-geocentric coordinate system (CS-95) with strongly outdated ellipsoid parameters (the Krassovsky 1940 ellipsoid) in 2021, Russian geodesists plan to switch to a geocentric system with an ellipsoid, the parameters of which coincide with the parameters of the best ellipsoid with an accuracy of $1 \mathrm{~m}$. (Groten, 2000; Torge, 2001; Standartinform, 2017). In the transition to the new GCS-2011 system, Russian surveyors will also have problems related to the area of the parcels. However, taking into account the fact that the boundaries and prime meridians of the zones in the Gauss-Krüger projection are the same for the CS-95 and GCS-2011 coordinate systems, problems in area changes associated with the properties of the Gauss-Krüger projection will be minimized. The main reason for the discrepancy between the areas of the parcels will be the difference between the centers of spatial rectangular coordinates, the orientation of the axes and the parameters of the reference ellipsoids. Since the discrepancy between the spatial rectangular coordinates and the parameters of the reference ellipsoid between the systems CS-95 and GCS-2011 is an order of magnitude larger than the corresponding values between the systems CS-63 and UCS-2000, the difference between the areas will also be an order of magnitude larger. But since this difference, judging from Figure 1, is a regular and monotonous function, therefore it will be much easier to take it into account.

\section{Conclusions}

The difference between the centers of spatial rectangular coordinates, the orientation of the axes and the parameters of the reference ellipsoids changes the area of the parcel by an amount whose maximum value is equal to 0.012 sq. $\mathrm{m}$.
Deformations between the coordinate systems CS-63 and UCS-2000 change the area by an amount whose maximum is equal to 0.277 sq. $\mathrm{m}$.

The difference between the area of the parcel in the Gauss-Krüger projection, associated with the properties of the projection itself, when transition from CS-63 to UCS2000, can reach 1.95 sq. m. In the transition from CS-63 to LCS, based on the UCS-2000, this difference can reach 7.020 sq. m. (LCS-35).

Thus, the main reason for the discrepancy between the areas of the parcels is the property of the Gauss-Krüger projection to distort the areas.

\section{References}

Aleknavicius, A., \& Sinkeviciute, V. (2008). Kartografija: mokomoji knyga. Ardiva. http://vuzf.asu.lt/wp-content/uploads/ sites/6/2015/01/kartografija_0.pdf

Bugaevskij, L., \& Snyder, J. (1995). Map projections: A reference manual. Taylor \& Francis.

Derzhheokadastr. (n.d.). Pasporty Derzhavnoyi heodezychnoyi referentsnoyi systemy koordynat USK-2000 (in Ukrainian). https://dgm.gki.com.ua/files/image/3261067/Pasport_UA_ UCS-2000\%20to\%20ITRS_ITRF2000.pdf

Groten, E. (2000). Parameters of common relevance of astronomy, geodesy, and geodynamics. Journal of Geodesy, 74(1), 134-140. https://doi.org/10.1007/s00190-000-0134-0

Standartinform. (2017). Global'naya navigatsionnaya sputnikovaya sistema. Sistemy koordinat. Metody preobrazovaniya koordinat opredelyayemykh tochek. Mezhgosudarstvennyy standart (GOST 32453-2017) (in Russian).

http://www.gistoolkit.ru/download/laws/pravrf472.pdf

Kucher, O. (2012). Vnedreniye gosudarstvennoy referentsnoy sistemy koordinat Ukrainy. Problemy I Resheniya, 3(46), 67-73. (in Ukrainian). http://docplayer.ru/29191192-Vnedrenie-gosudarstvennoy-referencnoy.html

Minahropolityky. (2016). Poriadok vykorystannia Derzhavnoi heodezychnoi referentsnoi systemy koordynat USK-2000 pry zdiisnenni robit iz zemleustroiu (Zatverdzheno nakazom Ministerstva ahrarnoi polityky ta prodovolstva Ukrainy vid 02.12.2016 r. No. 509) (in Ukrainian).

http://zakon.rada.gov.ua/laws/show/z1646-16

Molnár, G., \& Timár, G. (2005). Determination of the parameters of the abridging Molodensky formulae providing the best horizontal fit. Geophysical Research Abstracts, 7, 01018.

Novikova, E., Palamar, A., Makhonko, S., Barna, A., \& Privalova, O. (2018). Transformation Parameters between UCS-2000 and WGS-84. Geodesy and Cartography, 44(2), 50-54. https://doi.org/10.3846/gac.2018.1830

Parsova, V., Gurskiene, V., \& Kaing, M. (2012). Real property cadastre in Baltic Countries. Jelgava. http://www.vzd.gov.lv/ files/real_property_cadastre_baltic_countries.pdf

Petrulyte, E. (1998). Elements of land cadastre in Lithuania. Geodesy and Cartography, 24(1), 33-38.

Rapp, R. (1991). Geometric geodesy. Part I. Department of Geodetic Science and Surveying, The Ohio State University, Department of Geodetic Science and Surveying, Columbus, Ohio.

Rapp, R. (1993). Geometric geodesy. Part II. Department of Geodetic Science and Surveying, The Ohio State University, Columbus, Ohio. 
Stuifbergen, N. (2009). Wide zone transverse mercator projection. Bedford Institute of Oceanography, Dartmouth, Nova Scotia. http://publications.gc.ca/site/eng/364667/publication.html

Timár, G., \& Molnár, G. (2013). Map grids and datums. Eötvös Lóránd University. https://www.researchgate.net/publication/259480162_Map_grids_and_datums

Torge, W. (2001). Geodesy. W. de Gruyter. https://doi.org/10.1515/9783110879957

Urozhay. (1998). Prohrama stvorennya avtomatyzovanoyi systemy vedennya derzhavnoho zemel'noho kadastru. In Zemel' $n i$ vidnosyny v Ukrayini. Zakonodavchi akty i normatyvni dokumenty. Kyyiv (in Ukrainian).

Zakatov, P. (1962). A course in higher geodesy. Translated from Russian by Israel Program for Scientific Translation, for National Science Foundation, OTS 61-31212. 